\title{
Acute Cardiovascular Effects of Marijuana Use
}

\author{
Mehrnaz Ghasemiesfe, $M D^{7}$ (D) Divya Ravi, $M D, M P H^{2}$, Thomas Casino, $M D^{3}$, \\ Deborah Korenstein, $\mathrm{MD}^{4,5}$, and Salomeh Keyhani, MD, MPH 6,7
}

'Internal Medicine, Advocate Illinois Masonic Medical Center, Chicago, IL, USA; ${ }^{2}$ Internal Medicine, The Wright Center for Graduate Medical Education, Scranton, PA, USA; ${ }^{3}$ Division of Cardiology, University of Michigan, Ann Arbor, MI, USA; ${ }^{4}$ General Internal Medicine Service, Memorial Sloan Kettering Cancer Center, New York, NY, USA; ${ }^{5}$ Department of Medicine, Weill Cornell Medical College, New York, NY, USA; ${ }^{6}$ Northern California Institute of Research and Education, San Francisco Veterans Affairs Medical Center, San Francisco, CA, USA; ${ }^{7}$ Department of General Internal Medicine, UCSF Division of General Internal Medicine, San Francisco, CA, USA.

J Gen Intern Med 35(3):969-74

DOI: $10.1007 / \mathrm{s} 11606-019-05235-9$

(c) Society of General Internal Medicine 2019

\section{INTRODUCTION}

One out of 7 adults used marijuana in 2017. ${ }^{1}$ The concentration of tetrahydrocannabinol (THC), the primary psychoactive component of marijuana is increasing in commercially available products. ${ }^{2}$ However, there is little safety data available on the acute effects of cannabis outside of its psychoactive effects. One area of interest is the acute cardiovascular effects of marijuana given the ubiquitous presence of endocannabinoid receptors in the myocardium, coronary endothelium, and vascular endothelial and smooth muscle cells. ${ }^{3}$ We conducted a systematic review to examine the acute cardiovascular effects of marijuana use.

\section{METHODS}

We searched PubMed, MEDLINE, EMBASE, PsychINFO, and Cochrane Library for all Englishlanguage experimental studies examining marijuana use and acute cardiovascular effects between January 1, 1975, and March 31, 2018. Our search using MeSH terms outlined in Figure 1 yielded 1791 articles. We exclude articles with less than 20 participants. Two reviewers (M.G. and D.R.) selected 997 abstracts for review of which 80 met inclusion criteria and were selected for full text review. Two papers were added via author and reference tracking. Inter-rater reliability for the abstract selection process and the concurrent decision to include the article was excellent (Cohen kappa 0.87). We discussed the overall strength of evidence as a group for each outcome and graded it as insufficient, low, moderate, or high risk of bias (ROB) using methods outlined by the AHRQ. ${ }^{4}$ The protocol was registered on Prospero at the start of our review (No. CRD42016051297).

\section{RESULTS}

\section{Article Characteristics}

Fourteen articles focused on change of heart rate (HR), 6 on blood pressure (BP), and 2 on cerebrovascular circulation in response to marijuana administration. Among these, 7 were randomized clinical trials (RCT) and 7 were non-randomized experimental studies. Twelve out of 14 studies employed inhalation/smoking as the route of exposure. THC content in

Prior Presentations SGIM meeting Washington DC, April 19-22, 2017 presented.

Received May 29, 2019

Revised May 29, 2019

Accepted July 18, 2019

Published online August 13, 2019 


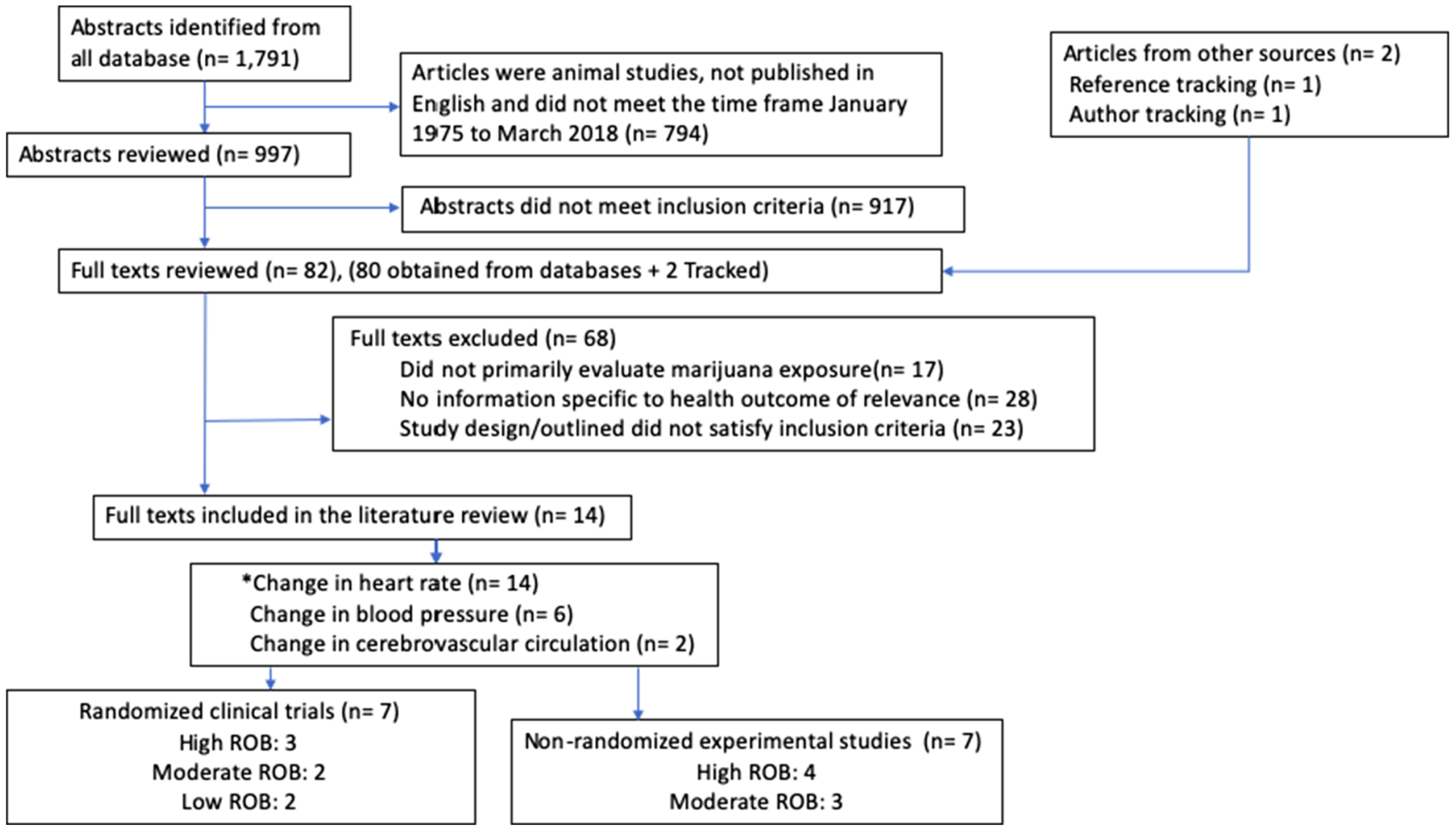

Figure 1 Flow of articles in the review. MeSH terms: (Marijuana OR Marihuana OR Tetrahydrocannabinol OR Cannabinoid) AND (Hypertension OR Hypotension OR Blood pressure OR Heart Rate OR Bradycardia OR Tachycardia OR Arrhythmia OR Hemodynamics OR Syncope OR Cerebrovascular Constriction). An asterisk indicates that some studies were assigned more than one outcome label and are counted twice.

smoke ranged from 1.5 to $3.6 \%$ per cigarette (equal to 14 to $35 \mathrm{mg}$ ). The highest dose of THC administered as edible or an injection was 17.5 and $5 \mathrm{mg}$, respectively. Half the articles were rated as high ROB (Table 1).

\section{Heart Rate}

All 14 studies (7 RCTs and 7 non-randomized experimental) rated as low to high ROB reported marijuana use was associated with tachycardia. The 2 low ROB RCT studies reported increase in HR after exposure to $3.55 \%$ smoke, $8 \mathrm{mg}$ oral, or $4 \mathrm{mg}$ injection THC. Two moderate ROB RCTs found an increase in HR in a dosedependent manner. Two non-randomized studies (moderate ROB) found a linear association between use and tachycardia. The last moderate ROB (non-randomized experimental) study reported all forms of marijuana $(1.83 \%$ smoked, $17.5 \mathrm{mg}$ oral THC, and $2 \mathrm{mg}$ synthetic nabilone) increased HR.

\section{Blood Pressure}

Six studies examined BP as an outcome (2 RCTs, and 4 nonrandomized experimental studies). Findings were mixed. In one study (RCT, low ROB) exposure to $3.55 \%$ THC per cigarette or $4 \mathrm{mg}$ THC per injection showed a drop in systolic BP $(p<0.01)$. The non-randomized study (moderate ROB) reported a linear association between marijuana dose (1.75 to
$3.55 \%$ ) and decreasing systolic BP. The remaining 4 high ROB studies had mixed findings with 3 studies showing no effect and one study reporting an increase in BP.

\section{Cerebrovascular Circulation}

Exposure to $3.55 \%$ THC per cigarette or $4 \mathrm{mg}$ THC injection (RCT, low ROB) showed drop in cerebral blood velocity $(p<0.007)$ while administration of $20 \mathrm{mg}$ THC per cigarette (equal to $2.08 \% \mathrm{THC}$ ) in a second study (non-randomized study, high ROB) showed no association with change in global cerebral blood flow (Table 1).

\section{DISCUSSION}

Low strength evidence suggests that marijuana use is associated with tachycardia. There was insufficient evidence on the relationship between marijuana use and acute changes in blood pressure and cerebrovascular circulation.

While the psychoactive effects of THC are well known, ${ }^{5}$ our review suggests that low concentrations of THC can cause tachycardia which may have health implications for older adults with vascular disease. The studies included this review had lower concentration of THC compared with products currently on the market. The highest dose of THC used in 
Table 1 Summary of Experimental Studies that Examined Exposure to Marijuana and Acute Cardiovascular Changes

\begin{tabular}{|c|c|c|}
\hline Study year, citation, and design & $\begin{array}{l}\text { Study } \\
\text { population }\end{array}$ & $\begin{array}{l}\text { Dose of MJ } \\
\text { exposure }\end{array}$ \\
\hline $\begin{array}{l}\text { Klumpers LE, et al. } 2012 \text { "Novel } \\
\text { Delta (9) THC formulation Namisol } \\
\text { (R) has beneficial pharmacokinetics } \\
\text { and promising pharmacodynamic ef- } \\
\text { fects." Br J Clin Pharmacol. RCT }\end{array}$ & $\begin{array}{l}21 \text { healthy MJ } \\
\text { users, age } 18 \text { to } \\
55 \text {, mean age } \\
21.6\end{array}$ & $\begin{array}{l}\text { Panel I: } 5 \mathrm{mg} \text { oral } \\
\text { or sublingual } \\
\text { THC. Panel II: } 6.5 \\
\text { or } 8 \text { mg oral THC } \\
\text { or matching } \\
\text { placebo }\end{array}$ \\
\hline
\end{tabular}

Cooper, et al. 2009 "Comparison of subjective, pharmacokinetic, and physiological effects of marijuana smoked as joints and blunts." Drug and alcohol dependence. RCT
24 young healthy current MJ users, age 21 to 45 , mean age 25.5
MJ blunt: 1.8 , $3.6 \% \mathrm{THC}$ or $\mathrm{MJ}$ cigarette: 1.8 , $3.6 \% \mathrm{THC}$ or placebo
D'souza, et al. 2008 "Blunted psychotomimetic and amnestic effects of $\Delta$-9-tetrahydrocannabinol in frequent users of cannabis." Neuropsychopharmacology. RCT
Mathew, et al. 2003 "Postural syncope after marijuana: a transcranial Doppler study of the hemodynamics." Pharmacol Biochem Behav. RCT
30 frequent cannabis users and 22 healthy controls, age 18 to 55 , mean age 26.9
$2.5 \mathrm{mg}$ or $5 \mathrm{mg}$ THC per injection or placebo
1.Tachycardia

Outcome
examined

1.Tachycardia

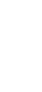

29 young healthy experienced MJ users, age $20-38$ mean age 25.5
$3.55 \%$ smoke THC or $0.2 \mathrm{mg} / \mathrm{ml}$ infusion THC in albumin (4 mg total) or placebo
1.Increase in pulse rate 2.Decrease in $\mathrm{BP}$ 3.CBV
20 young healthy current MJ users, age 21 to 34 , mean age 24.7
Chait Perry, et al. 1994 "Acute and residual effects of alcohol and marijuana, alone and in combination, on mood and performance." Psychopharmacology. RCT
Lex, et al. 1984 "Effects of acute marijuana smoking on pulse rate and mood states in women."

Psychopharmacolog. RCT
28 young female MJ users, age 21 to 36 , mean age 26.07
$3.6 \%$ THC per cigarette

1.Tachycardia (1.Techycardia 
Table 1. (continued)

\begin{tabular}{l}
\hline Study year, citation, and desig \\
\hline \\
Pihl, et al. 1978 "The effect of \\
marihuana intoxication on blood
\end{tabular}

marihuana intoxication on blood pressure." J Clin Psychol. RCT
Ponto, et al. 2004 "Effect of acute marijuana on cardiovascular function and central nervous system pharmacokinetics of [150] water: effect in occasional and chronic users." J Clin Pharmacol.

Experimental study
Mathew, et al. 1993

"Depersonalization after marijuana smoking." Biol Psychiatry.

Experimental study
48 young male experienced $\mathrm{MJ}$ users, age 18 to 35 , mean age 23

12 occasional and 12 chronic $\mathrm{MJ}$ users, age 20 to 36 , mean age 22.1
Low does MJ: $0.005 \mathrm{~g}$ or $0.003 \mathrm{~g}$ THC per cigarette, high dose $\mathrm{MJ}$ :

$0.006 \mathrm{~g}$ or

$0.0045 \mathrm{~g}$ THC per cigarette
$20 \mathrm{mg}$ THC per cigarette or placebo
1.Tachycardia 2.Increase/decrease in BP

3.Cerebral blood flow
1.Tachycardia

increase/decrease in BP

\section{Outcome}

examined

35 young healthy $1.75 \%, 3.55 \% \quad$ 1.Tachycardia MJ users, mean THC per cigarette age 27.1
2.Increase/decrease in BP
Mendelson, et al. 1984 "Reinforcing properties of oral $\Delta 9$ -

tetrahydrocannabinol, smoked marijuana, and nabilone: Influence of previous marijuana use.'

Psychopharmacology. *Experimental study
23 young healthy male MJ users, age 22 to 30 , mean age 25.5
$2 \mathrm{mg}$ oral nabilone or $1 \mathrm{~g}$ MJ cigarette (1.83\% THC) or $17.5 \mathrm{mg}$ oral THC or placebo
1.Tachycardia

$$
[F=3.08, p<0.02] \text {. }
$$

- Exposure to MJ showed significant increase in PR $(p<0.01)$ among intermittent and occasional users following MJ smoking. - Exposure to MJ showed a small but significant increase in PR $(p<0.05)$ among regular and intermittent users following oral $\mathrm{THC}$ administration. However, it showed a greater increase in PR among occasional users $(p<0.01)$.

- Exposure to MJ showed a small but statistically significant elevation in PR $(p<0.05)$ among all subjects following nabilone
High

High bias $^{\dagger}$ 
Table 1. (continued)

\begin{tabular}{l}
\hline Study year, citation, and design \\
\hline \\
Ashton, et al. 1981 "The seed and the \\
soil: effect of dosage, personality and \\
starting state on the response to delta \\
9 tetrahydrocannabinol in man." $B r J$ \\
Clin Pharmacol. Experimental study
\end{tabular}

Miller, et al. 1977 "Marijuana: Doseresponse effects on pulse rate, subjective estimates of potency, pleasantness, and recognition memory." Pharmacology. Experimental study
32 young healthy MJ users, mean age 23.4
32 healthy male moderate $\mathrm{MJ}$ users, age 21 to 28

$\begin{aligned} & \text { Dose of MJ } \\ & \text { exposure }\end{aligned}$
Exp1: $2.5 \mathrm{mg}$ or
$10 \mathrm{mg}$ THC per
cigarette.
Exp2: $8 \mathrm{mg} \mathrm{THC}$
per cigarette or
placebo

Outcome
examined

$5,10,15 \mathrm{mg}$ THC 1.Tachycardia per cigarette or placebo
Bernstein, et al. 1976 "Medical implications of marijuana use.” Am J Drug Alcohol Abuse. Experimental study
27 young healthy male MJ users, mean age 23.4

\section{$2.1 \%$ THC per cigarette}

Steadward, et al. 1975 "The effects of smoking marihuana on physical performance." Med Sci Sports. Experimental study
20 young healthy male MJ users, age 21 to 27 , mean age 23.1
$18.2 \mathrm{mg}$ THC per 1.Tachycardia cigarette or $1.4 \mathrm{mg}$ placebo

\begin{tabular}{|c|c|}
\hline Result in study & $\begin{array}{l}\text { Risk of } \\
\text { bias }^{\dagger}\end{array}$ \\
\hline $\begin{array}{l}\text { administration (no } \\
\text { tachycardia observed). } \\
\text { - Exposure to } 2.5 \text { mg THC } \\
\text { showed } 14.5 \% \text { increase in } \\
\text { HR } 1 \text { min after smoking } \\
\text { compared with the mean pre- } \\
\text { smoking rate in experiment } \\
1 \text {. It also showed } 34.8 \% \\
\text { increase in HR } 15 \text { min after } \\
\text { smoking of } 10 \text { mg THC. } \\
\text { - Exposure to } 8 \text { mg THC } \\
\text { showed increase in HR by } \\
\text { mean rise of } 12.6 \text { bpm } \\
13 \text { min after smoking } \\
\text { compared with placebo. } \\
\text { - Exposure to MJ showed } \\
\text { linear association between } \\
\text { MJ dose }(F=4.97 \text {, df }=3, \\
28 ; p<0.007), \text { time effect } \\
\text { (F-43.37, df }=3.84, \\
p<0.0001) \text { and dose*time } \\
\text { interaction }(F=8.03 \text {, df }= \\
9.84, p<0.0001) \\
\text { Exposure to MJ showed } \\
\text { increase in PR with dose up } \\
\text { to } 10 \text { mg with mild reversal } \\
\text { at } 15 \text { mg dose. } \\
\text {-Exposure to MJ showed } \\
\text { increase in PR following MJ } \\
\text { smoking. It also showed } \\
\text { tachycardia was more } \\
\text { prominent when the pulse } \\
\text { was counted with the subject } \\
\text { in the standing position } \\
\text { following MJ smoking. } \\
\text { - No significant association } \\
\text { between MJ smoking and } \\
\text { change in BP. } \\
\text { - Subjects randomized to } \\
\text { receive placebo or active MJ } \\
\text { cigarette. } \\
\text { - Exposure to MJ showed a } \\
\text { significant increase in HR } \\
(p<0.05) \text { from control to } \\
\text { MJ and from placebo to MJ. } \\
\text { - Exposure to MJ showed a } \\
\text { significant increase in SBP } \\
\text { and DBP ( } p<0.05) \\
\text { compared with controls and } \\
\text { placebo. }\end{array}$ & Moderate \\
\hline
\end{tabular}

receive place

- Exposure to MJ showed a significant increase in $\mathrm{HR}$ - Exposure to MJ showed a and DBP $(p<0.05)$ placebo. $(p<0.05)$ from control to compared with controls and
1.Tachycardia 2.Increase/decrease in BP showed $14.5 \%$ increase in

HR 1 min after smoking

1. It also showed $34.8 \%$

increase in HR 15 min after smoking of $10 \mathrm{mg}$ THC

- Exposure to $8 \mathrm{mg}$ THC showed increase in HR by

- Exposure to MJ showed

linear association between

MJ dose $(F=4.97, \mathrm{df}=3$,

$28 ; p<0.007)$, time effect

p

9.84, $p<0.0001)$

- Exposure to MJ showed 政

at $15 \mathrm{mg}$ dose.

-Exposure to MJ showed increase in PR following MJ smoking. It also showed tachycardia was more prominent when the pulse in the standing position following MJ smoking. - No significant association between MJ smoking and

change in BP. 2.Increase in $\mathrm{BP}$

BP, blood pressure; DBP, diastolic blood pressure; SBP, systolic blood pressure; HR, heart rate; $M G$, milligram; MJ, marijuana; PR, pulse rate; RCT, randomized control trial; $R R$, relative risk; THC, tetrahydrocannabinol; $C B V$, cerebral blood velocity; ANOVA, analysis of variance

*All studies examined the plant form of MJ except *study which also examined the synthetic form

${ }^{*}$ We used the Cochrane Risk of Bias Tool for Clinical Trials, and NIH Quality Assessment Tool for Controlled Intervention Studies to assess risk of bias $(R O B)$

experimental studies in our review was $3.6 \%$ per cigarette. Pre-rolled cannabis cigarettes available for purchase in cannabis dispensaries contain THC concentrations often exceeding $18 \%$ and reaching as high as $35 \%{ }^{2}, 6$ This is particularly concerning in older population with existing cardiovascular disease where acute hemodynamic changes may precipitate adverse outcomes.

Our study has several limitations. We may have overlooked relevant studies published outside of our predefined timeline. In addition, studies were conducted in young health populations limiting generalizability.
In conclusion, low concentrations of THC are associated with tachycardia among largely healthy and young populations. More safety data on use of high concentrations of THC and in clinically diverse populations are needed.

Corresponding Author: Mehrnaz Ghasemiesfe, MD; Internal Medicine, Advocate Illinois Masonic Medical Center, Chicago, IL, USA (e-mail: Mehrnaz.ghasemi@gmail.com).

Authors' Contribution SK had the idea for the study. SK, MG, DR, $D K$, and TC created the study design. MG and DR collected the data. SK verified the data. MG, DR, DK, and SK analyzed and interpreted 
the data. SK and MG wrote and revised the manuscript. All authors critically revised the manuscript and approved the final version for submission. SK is the guarantor.

\section{Compliance with Ethical Standards:}

Conflict of Interest: All authors declare that they have no conflict of interest.

Ethical Approval: Not needed.

Data Sharing: Data set available from corresponding author on request.

Transparency: The manuscript's guarantor (SK) affirms that this manuscript is an honest, accurate, and transparent account of the study being reported; that no important aspects of the study have been omitted; and that any discrepancies from the study as planned have been explained.

\section{REFERENCES}

1. Steigerwald S, Wong PO, Cohen BE, Ishida JH, Vali M, Madden E, et al. Smoking, vaping, and use of edibles and other forms of marijuana among US adults. Ann Intern Med. 2018; 169(12):890-892. https://doi.org/10. 7326/M18-1681.
2. Steigerwald S, Wong PO, Khorasani A, Keyhani S. The form and content of cannabis products in the United States. J Gen Intern Med. 2018. https://doi.org/10.1007/s11606-018-4480-0.

3. Pacher P, Bátkai S, Kunos G. The endocannabinoid system as an emerging target of pharmacotherapy. Pharmacol Rev. 2006;58:389-462.

4. Berkman ND, Lohr KN, Ansari M, McDonagh M, Balk E, Whitlock E, et al. Grading the Strength of a Body of Evidence When Assessing Health Care Interventions for the Effective Health Care Program of the Agency for Healthcare Research and Quality: An Update. Methods Guide for Comparative Effectiveness Reviews. (Prepared by the RTI-UNC Evidence-based Practice Center under contract no. 290-2007-10056-I.) AHRQ publication no. 13(14)-EHC130-EF. Rockville: Agency for Healthcare Research and Quality; November 2013. Accessed at https://ahrq-ehc-application.s3. amazonaws.com/media/pdf/methods-guidance-grading-evidence_ methods.pdf on 12 October 2017.

5. Volkow ND, Baler RD, Compton WM, Weiss SR. Adverse health effects of marijuana use. N Engl J Med. 2014;370(23):2219-27. https://doi.org/10. 1056/NEJMra1402309.

6. LaFrate A. Colorado Marijuana Study Finds Legal Weed Contains Potent THC Levels. NBCNews.com, Accessed at https:// marijuanaharmlessthinkagain.org/wp-content/uploads/2014/04/Colorado-Marijuana-Study-Finds-Legal-Weed-Contains-Potent-THC-Levels.pdf on 23 March 2015.

Publisher's Note Springer Nature remains neutral with regard to jurisdictional claims in published maps and institutional affiliations. 